\title{
Rural Cancer Health During the COVID-19 Pandemic
}

\section{Soumya J. Niranjan ${ }^{1} \cdot$ Claudia Hardy $^{2} \cdot$ Tara Bowman $^{2} \cdot$ Joseph Bryant $^{3} \cdot$ Molly Richardson $^{3} \cdot$ Meghan Tipre $^{3}$. Monica L Baskin ${ }^{3}$ (B)}

Published online: 28 August 2020

(C) American Association for Cancer Education 2020

To the Editor,

On March 11, 2020, the World Health Organization (WHO) announced that COVID-19 was a global pandemic [1]. Responses to combat it are robust in urban communities. However, rural communities and those largely populated by racial/ethnic minorities have received inadequate attention despite their higher death rates, increased risk, and are least likely to effectively manage a pandemic due to limited public health infrastructure [2] and rural hospital closures [3].

This letter discusses the impact of COVID-19 in rural Alabama and our efforts to eliminate cancer health disparities through education and outreach activities. It is especially important considering that this journal's readership has consistently investigated cancer health disparities and sought to address them through education in cancer prevention and survivorship. [4, 5] The O'Neal Comprehensive Cancer Center (O'Neal CCC) uses a community-based infrastructure to elevate cancer prevention messages via the Community Health Advisor (CHA) model which reaches Alabamians most at risk. [6, 7] Toward this goal, the Office of Community Outreach and Engagement (OCOE) has trained more than 1700 CHAs who are "natural helpers" in their communities.

In Alabama, $17 \%$ of the population lives in poverty [8] and most counties are considered non-metropolitan [9]. Many rural counties have at least 50\% African-Americans with per capita income at around $\$ 35,000$ [10]. They tend to be older,

Monica L Baskin

mbaskin@uabmc.edu

1 Department of Health Services Administration, University of Alabama at Birmingham, Birmingham, AL, USA

2 Office of Community Outreach and Engagement, O'Neal Comprehensive Cancer Center University of Alabama at Birmingham, Birmingham, AL, USA

3 Division of Preventive Medicine, University of Alabama at Birmingham, Medical Towers 618, 1717 11th Avenue South, Birmingham, AL 35205, USA have multiple comorbidities [11], are characterized by disproportionate lack of access to health services [8], and a predominately agricultural economy [12]. Additionally, 25\% of Alabamians live without internet access [13] an important factor associated with telemedicine usage [14].

The Alabama Department of Public Health (ADPH) has confirmed more than 81,000 cases of COVID-19, 1400 deaths, and less than $1 \%$ of the state's population tested. [15] Counties with the highest mortality rates are all rural with high rates of co-morbidities that increases the risk of becoming severely ill if infected [16].

COVID-19 has had a deep impact on our rural communities. The consequences of new physical distancing restrictions are most dramatically felt by church congregations, often the bedrock of social and spiritual life in the rural south and in African American communities. While some comply with the new mandates of distancing, others remain resistant as church and community gatherings have long been sources of support [17]. Rural funerals continue with large gatherings, including repast - the traditional meal served after the funeral service that provides as much comfort and fellowship as it does physical nourishment [16]. We have observed differences in the perceived threat of COVID-19. Firsthand accounts by our local staff suggest that social gatherings are continuing "since [residents] don't know anyone who has the disease or have died from it." While we know that there are multiple cases in each county, late onset of testing and limited publication of testing and mortality data in rural communities may be contributing to this false narrative.

In order to continue our mission during this pandemic, our staff has had to be resourceful in outreach and engagement approaches. Our in-person education has now been transferred to text messages, direct mailing, conference calls, and video conferences. We continue to monitor and share the availability of cancer-screening services at some local health departments. We are continuing to provide navigational services to reduce barriers to cancer treatments in geographically remote areas where poverty [18] and literacy [19] remain among the highest 
in the nation. We are also equipping our CHAs with COVID19 evidence-based communication materials, disseminate accurate information, and thereby combat misinformation. Additionally, we are hosting monthly educational sessions led by a licensed professional counselor to discuss mental health during these stressful times.

We are confident that the academic-community partnerships fostered over 20 years will endure despite the pandemic as we continue to serve communities in the areas of cancer prevention, screening, and survivorship.

Funding Information This is supported by the National Cancer Institute grant 3P30CA01348-47 and MSM/TU/UAB Comprehensive Cancer Center Partnership [NCI]: U54 CA118948.

\section{Compliance with Ethical Standards}

Disclaimer Views expressed are those exclusively of the authors and may not reflect those of the funding agencies.

\section{References}

1. Organization WH (2020) Pneumonia of unknown cause-China. Emergencies preparedness, response, Disease outbreak news, World Health Organization (WHO)

2. Cossman J, James W, Wolf JK (2017) The differential effects of rural health care access on race-specific mortality. SSM-Population Health 3:618-623

3. Kaufman BG, Thomas SR, Randolph RK, Perry JR, Thompson KW, Holmes GM, Pink GH (2016) The rising rate of rural hospital closures. J Rural Health 32(1):35-43

4. Torres E, Richman AR, Schreier AM, Vohra N, Verbanac K (2019) An evaluation of a rural community-based breast education and navigation program: Highlights and lessons learned. J Cancer Educ 34(2):277-284

5. Kocaöz S, Özçelik H, Talas MS, Akkaya F, Özkul F, Kurtuluș A, Ünlü F (2018) The effect of education on the early diagnosis of breast and cervix cancer on the women's attitudes and behaviors regarding participating in screening programs. J Cancer Educ 33(4): $821-832$

6. Lisovicz N, Johnson RE, Higginbotham J, Downey JA, Hardy CM, Fouad MN, Hinton AW, Partridge EE (2006) The deep South network for cancer control: building a community infrastructure to reduce cancer health disparities. Cancer. 107(S8):1971-1979

7. Hardy CM, Wynn TA, Huckaby F, Lisovicz N, White-Johnson F (2005) African American community health advisors trained as research partners: recruitment and training. Family \& Community Health 28(1):28-40

8. US. Census Bureau QuickFacts. https://www.census.gov/ quickfacts/fact/table/AL,US/PST045219. Accessed 22 Apr 2020

9. USDA RUCC Categorization System (2019) https://www.ers.usda. gov/data-products/rural-urban-continuum-codes.aspx. Accessed 22 Apr 2020

10. USDA's Economic Research Service (2020) https://data.ers.usda. gov/reports.aspx ?StateFIPS $=01 \&$ StateName $=$ Alabama $\& I D=$ 17854. Accessed 22 Apr 2020

11. Puma JE, Belansky ES, Garcia R, Scarbro S, Williford D, Marshall JA (2017) A Community-Engaged Approach to Collecting Rural Health Surveillance Data. J Rural Health 33(3):257-265

12. United States Department of Agriculture National Agricultural Statistics Service (2006) https://www.nass.usda.gov/. Accessed 22 Apr 2020

13. Ryan CL, Lewis JM (2015) Computer and internet use in the United States: 2015. US Department of Commerce, Economics and Statistics Administration, US

14. Wilcock AD, Rose S, Busch AB, Huskamp HA, Uscher-Pines L, Landon B, Mehrotra A (2019) Association between broadband Internet availability and telemedicine use. JAMA Intern Med 179(11):1580-1582

15. Alabama Department of Public Health Infectious Diseases \& Outbreaks Division https://alpublichealth.maps.arcgis.com/apps/ opsdashboard/index.html\#/6d2771 faa9da4a2786a509d82c8cf0f7. Accessed 22 Apr 2020

16. Preventive Cancer Screenings during COVID-19 Pandemic (2020) https://www.ehrn.org/wp-content/uploads/Preventive-CancerScreenings-during-COVID-19-Pandemic.pdf. Accessed 22 Apr 2020

17. Taylor RJ, Chatters LM, Lincoln KD, Woodward AT (2017) Church-based exchanges of informal social support among African Americans. Race Soc Probl 9(1):53-62

18. Jelavich M (2019) Rural and Urban Poverty Rates and the US Income Distribution. Paper presented at: Eastern Economic Association Meeting, New York

19. Roser M, Ortiz-Ospina E (2016) Literacy. Our World in Data

Publisher's Note Springer Nature remains neutral with regard to jurisdictional claims in published maps and institutional affiliations. 